\title{
Right-sided colon cancer with invasion of the duodenum or pancreas: A glimpse into our experience
}

\author{
NADEJDA COJOCARI $^{1 *}$, GABRIEL VIOREL CRIHANA $^{2}$, NICOLAE BACALBASA $^{1,3,4^{*}}$, \\ IRINA BALESCU ${ }^{5}$ and LEONARD DAVID ${ }^{1}$
}

\author{
${ }^{1}$ Department of Visceral Surgery, 'Fundeni' Clinical Institute, 022328 Bucharest; ${ }^{2}$ Department of Visceral Surgery, \\ Ilfov County Emergency Clinical Hospital, 22113 Bucharest; ${ }^{3}$ Department of Obstetrics and Gynecology, \\ 'Carol Davila' University of Medicine and Pharmacy, 020021 Bucharest; ${ }^{4}$ Department of Obstetrics and Gynecology, \\ 'I. Cantacuzino' Clinical Hospital, 030167 Bucharest; ${ }^{5}$ Department of Visceral Surgery, \\ 'Ponderas' Academic Hospital, 021188 Bucharest, Romania
}

Received July 16, 2021; Accepted August 16, 2021

DOI: $10.3892 / \mathrm{etm} .2021 .10813$

\begin{abstract}
Duodenal or pancreatic invasion in locally advanced right colon cancer (LARCC) is a challenging situation that can pose difficulties in its management. When the duodenum alone is invaded, the surgeon may undertake right hemicolectomy $(\mathrm{RH})$ en bloc with the affected patch of duodenum. The duodenal defect can be reconstructed using several techniques. When invasion of the pancreas is present, RH en bloc with duodenopancreatectomy (DP) is the treatment of choice. We present our experience regarding the treatment and prognostic results of this rare colon cancer form. We retrospectively reviewed the data of patients who underwent surgery for right-sided colon cancer with duodenal and/or pancreatic invasion between January 2004 and March 2020. Among the 110 patients with LARCC, pancreas and/or duodenum invasion was encountered in 22 patients, with a mean age of 49.5 years. From the 22 patients, 5 patients underwent palliative procedures, with a maximal survival of 15 months. Three patients underwent RH alone, with lethal outcome in the first year in $66 \%$ of the cases. $\mathrm{RH}$ en bloc with antrectomy was performed in 2 patients. Eight patients underwent RH with DP, with a 1-year survival of $75 \%(6 / 8)$ and a 5 -year survival of 50\% (3/6). Thirty-day mortality post-DP was noted in $25 \%(2 / 8)$ of the cases. Four patients underwent RH with limited duodenal resection, with no recurrence of disease at 11 to 39 months postoperatively. Among the duodenal defect restoration, simple duodenal
\end{abstract}

Correspondence to: Dr Nadejda Cojocari, Department of Visceral Surgery, 'Fundeni' Clinical Institute, 258 Fundeni Street, 022328 Bucharest, Romania

E-mail: nadya_md@yahoo.com

${ }^{*}$ Contributed equally

Key words: advanced colon cancer, multivisceral resection, ileal flap, pancreatoduodenectomy, duodenal invasion suture was practiced in 2 patients, duodenojejunostomy in one patient and pedicled ileal flap in 1 case. In conclusion, although postoperative mortality can be significant, en bloc resection for LARCC invading the duodenum and/or pancreas offers prolonged survival in a considerable number of patients.

\section{Introduction}

Locally advanced colon cancers constitute $10 \%$ of all colorectal malignancies at the time of diagnosis (1) and are more common in the rectosigmoid (66-89\%) (2).

The incidence of right-sided colon cancers (RSCCs) invading adjacent organs is rare (11-28\%) (3). Their management is particularly challenging especially if invasion of the duodenum or pancreas occurs. Multivisceral resections have proven their efficiency with satisfactory outcomes concerning recurrence status and survival rates (4). In duodenal and/or pancreatic invasion, the optimal technique utilized is right hemicolectomy ( $\mathrm{RH}$ ) with en bloc duodenopancreatectomy (DP) (5). Therefore, radical resection of the lesion in association with local lymph node dissection provides the opportunity of maximal local control (6). Nevertheless, the complexity of the procedure, the risks of postoperative morbidity and a poor patient general condition in T4 RSCC prompt the surgeon to opt for palliative treatment or limited duodenal resections. Limited duodenal resections show promising survival results if the margins of at least $1 \mathrm{~cm}$ from the invaded area are respected (7) and when the papilla of Vater and pancreas are intact. The intestinal integrity must be restored by one of the duodenal continuity reconstruction techniques if large duodenal defects are present. Several procedures have been proposed, including pedicled gastric flap (8), serosal jejunal patching (9), serosal ileal patching, mucosal jejunal patching (10) and duodenojejunostomy (11).

Herein, we present our experience regarding the management of RSCC invading the duodenum or pancreas; the aim of the study was to analyze the long-term outcomes after such resections. 


\section{Patients and methods}

We selected all of the patients with locally advanced right-sided colon cancer (LARCC) including the proximal two-thirds of the transverse colon, who were admitted into our 130-bed surgical department of 'Fundeni' Clinical Institute from January 2004 to March 2020. RSCC was considered locally advanced when adjacent structures or organs were involved. Patients who presented distant metastasis, peritoneal spread, vascular invasion or recurrent disease were excluded from the current study. From the patients with LARCC, the medical records of 22 patients with colon cancer invading the duodenum or pancreas were reviewed in detail. The data analyzed, retrospectively, included demographics, site, clinical presentation, imagistic findings, type of surgery, postoperative course, pathologic staging of the tumor according to the Union for International Cancer Control TNM system (www.uicc.org), pathologic grading, tumor size, postoperative morbidity, adjuvant treatment modalities and follow-up duration. Survival rates were calculated using Microsoft Excel program.

\section{Results}

Among the 110 patients with LARCC who underwent surgery at our department, the most frequently invaded structure was perinephric fat. Pancreas and duodenum involvement was encountered in 22 cases (19\%). Other sites of invasion are listed in Table I.

The mean age of the patients with pancreatic or duodenal involvement of the disease was 49.5 years and ranged between 25 and 77 years, with a prevalence of male patients over female patients $(16 / 6 ; 83 \% / 17 \%)$. The most frequent site of origin of RSCC involving the duodenum or pancreas was the hepatic flexure of the colon in 18 cases $(81 \%)$, followed by the ascending portion of the colon in $3(14 \%)$ cases and cecum in 1 case. Seventeen patients $(77 \%)$ had anemia at presentation. Other symptoms such as pain, altered bowel habits or weight loss were found in 15 patients $(68 \%)$, whereas 3 patients underwent emergency surgery for tumor perforation or hemorrhage. Eighteen patients $(81 \%)$ underwent a preoperative computed tomography (CT) scan. Duodenal/pancreatic involvement on CT scan was suspected in 11/18 (61\%) patients.

Intestinal bypass was practiced in 5/22 (22\%) cases, mostly due to patient comorbidities and age. Two of these patients had liver cirrhosis, one had a history of acute myocardial ischemia and stroke and two were over 75 years of age. The other 17 patients underwent $\mathrm{RH}, \mathrm{RH}$ en bloc with $\mathrm{DP}, \mathrm{RH}$ en bloc with antrectomy and proximal duodenal resection or RH with partial duodenectomy. Clinical data of patients who underwent resections are detailed in Table II.

Overall, 8/17 patients (47\%) underwent en bloc DP with standard reconstruction techniques. Palliative $\mathrm{RH}$ was practiced in 3 patients (18\%), because of the emergent nature of the surgical procedure (tumor perforation or hemorrhage). Another 2 patients underwent right extended hemicolectomy en bloc with antrectomy, when the first portion of duodenum was adherent to the colonic tumor. The limited excision of the duodenum was practiced in $4 / 17$ patients $(23,5 \%)$, followed by simple duodenorrhaphy in 2 patients, doudenojejunostomy in 1 case and pedicled ileal patch in one case. Mean tumor size in all the patients who underwent resection surgery was $7.5 \mathrm{~cm}$ and ranged between 3 and $15 \mathrm{~cm}$. In our ileal patch reconstruction case, the ileal patch was prepared from the distal $8 \mathrm{~cm}$ of the terminal ileum. After mesenteric pedicle preparation, the ileum was cut on the antimesenteric border, trimmed dimensionally so that it fits the duodenal diameter and sutured in double layer to the lateral wall of the duodenum (Fig. 1).

Upon histopathological analysis, 6 specimens from the $\mathrm{RH}$ with DP series presented pancreatic and duodenal invasion, 1 specimen presented pancreatic invasion alone, whereas in 1 case inflammatory adhesions to the gland were encountered. Coloduodenal fistula was present in 4 cases.

Among the 4 cases with limited duodenal resection, 3 patients presented invasion of the entire duodenal wall, including mucosa while the fourth patient had extrinsic invasion of the duodenal submucosa.

Meanwhile lymphatic node involvement was encountered in $50 \%$ of the entire study group.

The majority of the patients $(9 / 10 ; 90 \%)$ from both the limited duodenal resection and DP series, that survived the postoperative period, received adjuvant chemotherapy.

The 5-year survival rate in the RH with DP series could be calculated in cases that had surgery between 2004 and 2015 (6 patients) and was $50 \%$. Of the 3 patients with a lethal outcome, 2 patients died due to postoperative complications in the first 30 days; one of the patients died of pulmonary thromboembolism and the other one developed pancreatitis of the pancreatic stump and pneumonia. The third patient succumbed to local recurrence 12 months after surgery.

Postoperative morbidity was noted in 2 cases $(25 \%)$. Both patients developed pancreatic leakage, successfully treated during postoperative recovery.

The 5-year survival data for the 2 patients that underwent RH with DP between 2016 and 2020 is not yet available. Both are alive without evidence of local recurrence at 4 years and at 31 months respectively after surgery.

In the limited duodenal resection series, the 5-year survival rates are not yet available. However, no 30-day mortality was observed. All patients are alive at 11 to 39 months postoperatively.

Of the 3 patients with palliative RH, only 1 patient survived more than 5 years. It was determined that he presented T3 invasion with inflammatory adhesions to the duodenum on the histopathological analysis. Although he was submitted to chemotherapy, he developed lung metastasis 2 years after the first intervention, which was successfully resected and liver metastasis 2 years after the second intervention, successfully resected as well. Among the cases submitted to palliative surgery (intestinal bypass) the maximum length of survival was 15 months.

\section{Discussion}

Colon cancer is one of the most frequent malignancies, with 14,000 new cases being diagnosed annually in Romania (12). Locally advanced colon cancers invading the duodenum/ pancreas are a less common finding, with an incidence of $11 \%$ (13). We investigated only patients with LARCC and found the prevalence of duodenum/pancreas involvement in 19\%, being outweighed by perirenal fat invasion, in $29 \%$ of cases. The rarity of pancreatic/duodenal involvement is reflected in 
Table I. Secondary sites of invasion ${ }^{\mathrm{a}}$.

Organ/tissue involved

No. of patients $(\mathrm{N}=110)$

\begin{tabular}{lr}
\hline Psoas muscle & 4 \\
Stomach & 16 \\
Gallbladder & 10 \\
Abdominal wall & 27 \\
RLL/ovary & 9 \\
Liver & 5 \\
Small bowel & 19 \\
Perirenal fat & 32 \\
Kidney & 4 \\
Peritoneum & 9 \\
Ureter & 2 \\
Other parts of the colon & 5 \\
Duodenum/pancreas & 22 \\
\hline
\end{tabular}

aSome patients presented with more than one adjacent organ/structure invaded. RLL, right lombo-ovarian ligament.

the paucity of the reported case series in the literature (14). Furthermore, the medical literature may be deprived of studies because of the complexity of the operative technique for en bloc resection of the right colon in continuity with DP, which discourages the surgeons to make radical decisions (15) and the lack of popularity for limited duodenal resections, in cases of duodenal involvement alone.

Despite advances in preoperative screening and clinical imaging, adjacent organ involvement is often discovered during surgery (16). Some authors pointed out that palpable and immobile tumors are predictive for local invasion $(3,14)$. In our study the most persistent symptom was anemia (77\%), followed by abdominal pain, with tumor palpability being described only in one case. However, the results may be biased because of the tendency of modern surgeons to rely on imaging exams rather than clinical features. Preoperative imaging in our series was able to detect local duodenal/pancreatic invasion in $60 \%$ of the cases. If duodenocolic fistula is present, then barium enema is the best option for its detection, since increased colic pressure redirects bowel contents towards the duodenum (17). Of the 4 cases with duodenocolic fistula in our series, one was investigated by means of barium enema. The other 2 patients underwent endoscopy and in the last case fistula was detected intraoperatively.

Even if adherence between the colon and duodenum is easily assessed after mobilization of the colon, it is difficult for the surgeon to rule out whether adherence is of a malignant nature or due to inflammatory processes, since $40 \%$ of adhesions are a result of local inflammatory response (18). Adhesion dissection may lead to malignant dissemination (19) and is associated with recurrence rates of $90-100 \%$ (20). Yet, in our study, histopathological exam showed malignant infiltration of the adherent part to the duodenum/pancreas in the majority of cases $(15 / 17 ; 88 \%)$. Dissection of adhesions in the setting of emergent RH was practiced in 3 patients, of which 2 patients had R1 margins on histopathology.
Generally, in making a decision on what type of surgery to perform for patients with LARCC, one should remind oneself of Hippocrates's quote: 'For extreme diseases, extreme remedies are most fitting' (13).

Since patients undergoing digestive bypasses prove to have a median survival of 9 months (21), this technique should be reserved to cases with malignant distal spread, with poor survival because of comorbidities or in cases with increased operative risk. In our study, 5 patients underwent digestive bypass; although, it was hard to determine retrospectively if any of these patients could have benefited from resective surgery.

Incomplete resection including organ separation is associated with a mean patient survival time of 11 months (21). In our study, out of 3 cases with incomplete resection, 2 cases survived for 7 and 11 months, respectively, which confirms low survival in this group.

By contrast, patients who undergo en bloc multivisceral resection were found to exhibit a disease-free survival rate of $56 \%$ at 1 to 5 years of follow-up (22). In addition, local invasion of adjacent organs is not a statistically more unfavorable prognostic factor than one to five lymph node metastases (3). However, lymph node involvement in LARCC has a supplementary negative impact on survival (23). In our series, $8 / 14$ patients with en bloc resection had lymph node involvement, but no correlation was noted between lymph node involvement and the survival rate.

En bloc resection of the colon and pancreatic head was initially performed by Linton in 1941, as a 2-stage procedure, preceded by digestive bypass for patient nutritional status improvement (24). A decade later, several authors modified it to a 1-stage procedure $(25,26)$. Yet, the first reports and studies did not confirm a favorable prognosis. It was only recently that RH with DP for LARCC began to regain attention, with 5-year survival rates of $54 \%$ (4). The increase in the safeness of the procedure is due to parenteral nutrition possibilities in patients with preoperative bad health status and weight loss $(27,28)$ and to improvements in the surgical technique (23). In our series, however, a 25\% 30-day postoperative mortality rate occurred, possibly due to the lack of careful selection of cases in the early RH with DP attempts.

Moreover, DP permits en bloc dissection of peripancreatic and perigastric lymph nodes (29), a fact that may have additional benefits on survival. In our DP series, a 1-year survival rate was achieved in $75 \%$ of the patients and a 5 -year survival in $50 \%$ of the patients.

If the duodenal sidewall is affected, with papilla of Vater free of invasion, a surgeon may take into consideration limited duodenal resection, especially in patients with high perioperative risks and comorbidities (15). No certain evidence exists that survival in regards to limited duodenal resections is worse than in DP, since randomized studies are absent and scientific data are limited to several case reports and case series (15,30-33). Nonetheless, the procedure of limited duodenal resection has been described since 1963 (34).

When less than one-third of the duodenal wall is excised, the easiest method of defect closure is simple duodenorrhaphy (5). In the current series, simple transverse closure was used in 2 patients, with no postoperative complications noted. If taking into consideration the reported experience of the management of traumatic duodenal injuries, there is a certain risk of tension 
Table II. Clinical data and outcome of the patients who underwent resective surgery.

\begin{tabular}{|c|c|c|c|c|c|c|c|c|c|c|}
\hline Age (years)/sex & Surgery ${ }^{\mathrm{a}}$ & Grade & T stage & Org. inv. ${ }^{\mathrm{b}}$ & $\mathrm{CDF}$ & $\mathrm{N}$ stage & 30DPOM & Chemo. ${ }^{c}$ & Follow-up & Status \\
\hline $25 / M$ & DP & G1 & 4 & $\mathrm{P}$ & No & 0 & No & FOLFOX & 16 years & NED \\
\hline $61 / \mathrm{M}$ & DP & G1 & 4 & $\mathrm{D}+\mathrm{P}$ & Yes & 1 & Yes & - & - & - \\
\hline $52 / \mathrm{M}$ & DP & G2 & 4 & $\mathrm{D}+\mathrm{P}$ & Yes & 1 & No & FOLFOX & 12 months & DOD \\
\hline $62 / \mathrm{M}$ & $\mathrm{RH}+\mathrm{G}$ & G2-G3 & 4 & D1 & No & 1 & No & $\mathrm{C}$ & 15 years & NED \\
\hline $71 / \mathrm{M}$ & RH & G1 & 3 & No & No & 0 & No & XELOX & 9 years & ROD \\
\hline $65 / \mathrm{M}$ & $\mathrm{DP}+\mathrm{N}$ & $\mathrm{G} 2$ & 4 & $\mathrm{D}+\mathrm{P}+\mathrm{K}$ & No & 2 & Yes & - & - & - \\
\hline $64 / \mathrm{F}$ & $\mathrm{PP}-\mathrm{DP}+\mathrm{N}$ & G1-G2 & 4 & $\mathrm{D}+\mathrm{P}+\mathrm{K}$ & Yes & 0 & No & XELOX & 6 years & NED \\
\hline $63 / / F$ & DP & $\mathrm{G} 2$ & 3 & No & No & 0 & No & $\mathrm{C}$ & 6 years & NED \\
\hline $65 / \mathrm{M}$ & DP & $\mathrm{G} 2$ & 4 & $\mathrm{D}+\mathrm{P}$ & No & 1 & No & FOLFOX & 4 years & NED \\
\hline $75 / \mathrm{M}$ & RH & G2-G3 & 4 & D & No & 0 & No & XELOX & 11 months & DOD \\
\hline $62 / \mathrm{M}$ & $\mathrm{D}$ & G1-G2 & 4 & $\mathrm{D}$ & No & 2 & No & XELOX & 39 months & NED \\
\hline 69/M & DP & $\mathrm{G} 2$ & 4 & $\mathrm{D}+\mathrm{P}$ & Yes & 1 & No & OX & 31 months & NED \\
\hline $76 / \mathrm{F}$ & $\mathrm{D}$ & G3 & 4 & $\mathrm{D}$ & No & 0 & No & No & 24 months & NED \\
\hline $74 / \mathrm{F}$ & $\mathrm{RH}$ & G3 & 4 & $\mathrm{P}$ & No & 1 & No & No & 7 months & DOD \\
\hline $66 / \mathrm{M}$ & $\mathrm{D}$ & G1 & 4 & $\mathrm{D}$ & No & 0 & No & XELOX & 24 months & NED \\
\hline $55 / \mathrm{M}$ & $\mathrm{D}$ & $\mathrm{G} 2$ & 4 & $\mathrm{D}$ & No & 2 & No & XELOX & 11 months & NED \\
\hline $52 / \mathrm{M}$ & $\mathrm{RH}+\mathrm{G}$ & G1-G2 & 4 & D1 & No & 0 & No & N/A & N/A & N/A \\
\hline
\end{tabular}

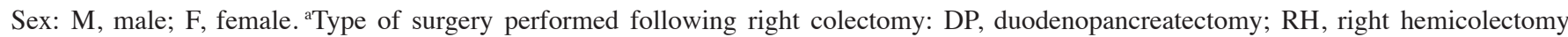

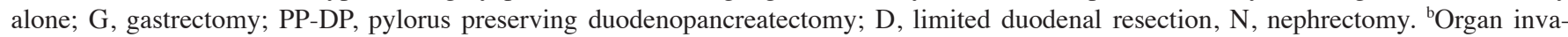
sion: P, pancreas; D, duodenum; K, kidney; CDF, coloduodenal fistula. ${ }^{\mathrm{C} C h e m o t h e r a p y: ~ F O L F O X, ~ l e u c o v o r i n e, ~ o x a l i p l a t i n ~ a n d ~ f l u o r o u r a c i l ; ~}$ C, capecitabine; OX, oxaliplatin; XELOX, capecitabine plus oxailplatin. Status: NED, no evidence of disease; DOD, dead of disease; ROD, recurrence of disease; 30DPOM, 30 days postoperative mortality; N/A, data not available.
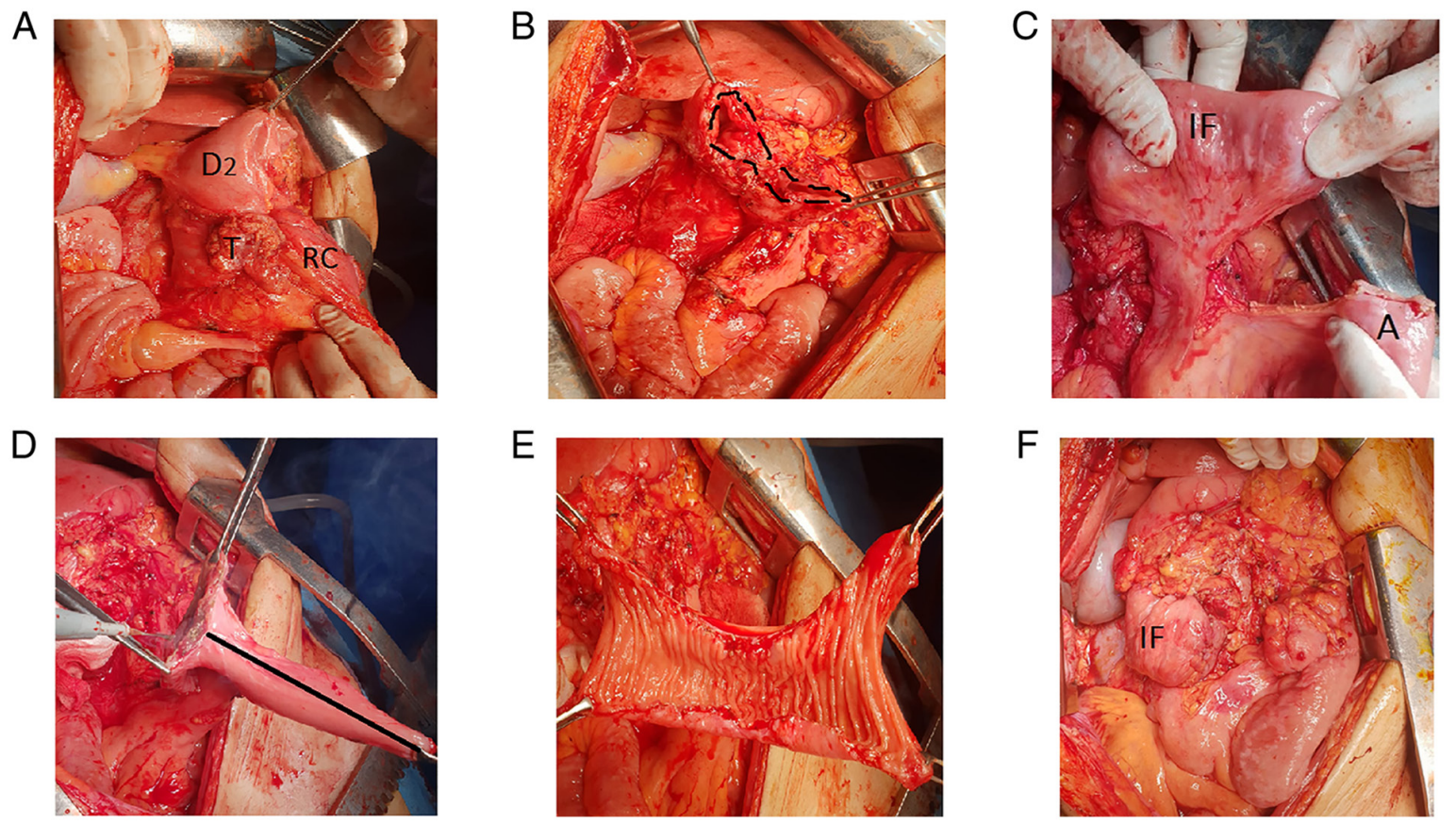

Figure 1. (A) Colon tumor adherent to the duodenum: D2, second part of the duodenum; T, tumor; RC, right colon. (B) En bloc resection of the colon tumor with a patch of duodenal wall The broken line delineates the area of duodenal defect. (C) Pediculization of the ileal flap: IF, ileal flap; A, ascending portion of the ileum (D) Cutting of the antimesenteric border. The black line indicates the exact place where the flap was cut along its antimesenteric border. (E) Trimming the flap according to the duodenal defect diameters. (F) Ileal flap sutured to the duodenal defect: IF, ileal flap.

development on the suture line and duodenal disruption even in small defects (35). Therefore, patch repair should always be considered. The usual duodenal defect repair is Roux-en-y duodenojejunostomy (9). Nonetheless, it has the disadvantages 
of delivering bile and pancreatic juice more distally in the small intestine (36) and requires an additional anastomosis. The intestinal loop can be difficult to mobilize in cases of short mesentery (37). Finally, it can lead to internal hernias because of the formation of wide mesenteric defects (38).

Pedicled ileal grafting seems to be the perfect solution for large defects. First of all, no additional cutting of the digestive tract at other sites is needed. It does not create a nonanatomical bypass $(7,11)$ and can be retroperitonized without affecting the ileocolic anastomosis. Finally, the patch width is easily adaptable, avoiding the formation of duodenal stenosis or pouchitis (38). Data on the outcomes of en bloc limited duodenal resection are lacking, since a limited number of cases have been performed and reported. Based on the existing literature, Hamed et al estimated a 3 -year survival rate of $70 \%$ after limited duodenal resections, comparable to the 3-year survival rate after DP (37). Our 4 patients with limited duodenal resection are all alive after 1 year.

Recent studies have shown that neither tumor diameter nor duodenocolic fistula presence (15) influence prognosis after en bloc resection. Of the 4 patients with duodenocolic fistula in our series, 2 are alive and disease-free at 6 years and 31 months, respectively.

In conclusion, en bloc resection in RSCC invading the duodenum/pancreas appears to control the disease in a considerable number of patients. More studies are needed to ascertain which method accompanying RH, DP or limited duodenal resection, is preferable when duodenum alone is involved. When limited duodenal resection is chosen, the ileal pedicled flap technique provides the most benefit to the duodenal defect closure.

\section{Acknowledgements}

Not applicable.

\section{Funding}

No funding was received.

\section{Availability of data and materials}

All data generated or analyzed during this study are included in this published article.

\section{Authors' contributions}

NC collected data, performed the literature search and prepared the drafted paper. IB analyzed data and edited the drafted paper. GVC and NB provided the supplementary material (figure) and performed the statistical/grammatical revisions to the manuscript. LD and NB provided revisions to the scientific content of manuscript. All authors read and approved the final manuscript for publication.

\section{Ethics approval and consent to participate}

Not applicable as the study was retrospective and the data were completely anonymized. Informed consent was obtained from all individual participants involved in the study.

\section{Patient consent for publication}

Informed consent was obtained for use of all images published in the study.

\section{Competing interests}

The authors declare that they have no competing interests.

\section{Authors' information}

Nadejda Cojocari: ORCID ID: 0000-0003-3720-0869.

\section{References}

1. Gebhart C, Meyer W, Ruckriegel S and Meier U: Multivisceral resection of advanced colorectal carcinoma. Langenbecks Arch Surg 348: 194-199, 1999.

2. Harish K, Narayanaswamy Y and Nirmala S: Treatment outcomes in locally advanced colorectal carcinoma. Int Semin Surg Oncol 1: 8, 2004.

3. Polk Jr HC: Extended resection for selected adenocarcinomas of the large bowel. Ann Surg 175: 892-899, 1972.

4. Curley SA, Evans DB and Ames FC: Resection for cure of carcinoma of the colon directly invading the duodenum or pancreatic head. J Am Coll Surg 179: 587-592, 1994.

5. Kapoor S, Das B, Pal S, Sahni P and Chattopadhyay TK: En bloc resection of right-sided colonic adenocarcinoma with adjacent organ invasion. Int J Colorectal Dis 21: 265-268, 2006.

6. Lee WS, Lee WY, Chun HK and Choi SH: En bloc resection for right colon cancer directly invading duodenum or pancreatic head. Yonsei Med J 50: 803-806, 2009.

7. Lianwen Y, Jianping Z, Guoshun S, Dongcai L and Jiapeng Z: Pedicled Ileal flap for duodenal defect after right hemicolectomy. Hepatogastroenterology 57: 493-496, 2010.

8. Moriura S, Ikeda S, Ikezawa T, Naiki K, Sakai T, Yokochi K and Kuroda M: Hepatocellulcar carcinoma invading the duodenum: Combined resection of the lateral duodenum and repair with a pedicled gastric flap. Dig Surg 12: 136-139, 1995.

9. Walley B and Goco I: Duodenal patch grafting. Am J Surg 140: 706-708, 1980.

10. Aswaf I, Thomson NW and Huang CL: The open jejunum: A patch for large duodenal defects. Am J Surg 131: 601-602, 1976.

11. Ishiguro S, Moriura S, Kobayashi I, Tabata T, Yoshioka Y and Matsumoto T: Pedicled ileal flap to repair large duodenal defect after right hemicolectomy for right colon cancer invading the duodenum. Surg Today 34: 386-388, 2004.

12. Ionescu EM, Tieranu CG, Maftei D, Grivei A, Olteanu AO, Arbanas T, Calu V, Musat S, Mihaescu-Pintia C and Cucu IC: Colorectal cancer trends of 2018 in romania-an important geographical variation between northern and southern lands and high mortality versus european averages. J Gastrointest Cancer 52: 222-228, 2021.

13. Hakimi A, Rosing D, Stabile B and Petrie AB: En bloc resection of the duodenum for locally advanced right colon adenocarcinoma. Am Surg 73: 1063-1066, 2007.

14. Koea JB, Conlon K, Paty PB, Guillem JG and Cohen AM: Pancreatic and duodenal resection or both for advanced carcinoma of the right colon: Is it justified? Dis Colon Rectum 43: 460-465, 2000.

15. Cirocchi R, Partelli S, Castellani E, Renzi C, Parisi A, Noya G and Falconi M: Right hemicolectomy plus pancreaticoduodenectomy vs partial duodenectomy in treatment of locally advanced right colon cancer invading pancreas and/or only duodenum. Surg Oncol 23: 92-98, 2014.

16. Charnsangavej $\mathrm{C}$ and Whittey $\mathrm{N}$ : Metastases to the pancreas and peripancreatic lymph nodes from carcinoma of the right side of the colon: CT findings in 12 patients. AJR Am J Roentgenol 160: 49-52, 1993.

17. Melissas J, Schoretsantis G, Daskalakis M and Tsiftsis D: Sigmoidoduodenal fistula as a rare complication of colonic carcinoma: Report of a case. Surg Today 33: 623-625, 2003.

18. Kroneman H, Castelein A and Jeekel J: En bloc resection of colon carcinoma adherent to other organs: An efficacious treatment? Dis Colon Rectum 34: 780-783, 1991. 
19. Gall FP, Tonak J, Altendorf A and Kuruz U: Operative tactics and results in extensive operations for colorectal cancer. Langenbecks Arch Chir 366: 445-450, 1985 (In German).

20. McGlone T, Bernie W and Elliott D: Survival following extended operations for extracolonic invasion by colon cancer. Arch Surg 117: 595-599, 1982.

21. McSherry CK, Cornell GN and Glenn F: Carcinoma of the colon and rectum. Ann Surg 169: 502-509, 1969.

22. Sugarbaker ED: Coincident removal of additional structures in resections for carcinoma of the colon and rectum. Ann Surg 123: 1036-1046, 1949.

23. Fuks D, Pesaux P, Tuech JJ, Mauvais F, Brehant O, Dumont F, Chatelain D, Yzet T, Joly JP, Lefebure B, et al: Management of patients with carcinoma of the right colon invading the duodenum or pancreatic head. Int J Colorectal Dis 23: 477-481, 2008.

24. Linton RR: Two stage operation for carcinoma of transverse colon producing duodeno-colic fistula. Report of two cases. Arch Surg 48: 197-207, 1944.

25. Van Prohaska J, Govostis MC and Wasick M: Multiple organ resection for advanced carcinoma of the colon and rectum. Surg Gynecol Obstet 97: 177-182, 1953.

26. Mills JRM and Mills JR: Malignant duodenocolic fistula-report of a case treated successfully by mass resection. Con J Surg 3 : 91-92, 1959.

27. Yoshimi F, Asato Y, Kuroki Y, Shioyama Y, Hori M, Itabashi M, Amemiya R and Koizumi S: Pancreatoduodenectomy for locally advanced or recurrent colon cancer: Report of two cases. Surg Today 29: 906-910, 1999.

28. Saiura A, Yamamoto J, Ueno M, Koga R, Seki M and Kokudo N: Long-term survival in patients with locally advanced colon cancer after en bloc pancreaticoduodenectomy and colectomy. Dis Colon Rectum 51: 1548-1551, 2008.

29. Izumi Y, Ueki T, Naritomi G, Akashi Y, Miyoshi A and Fukuda T: Malignant duodenocolic fistula: Report of a case and considerations for operative management. Surg Today 23: 920-925, 1993
30. Bacalbasa N, Balescu I, Tanase A, Pautov M, brezean I, Vilcu M and Brasoveanu V: Spleno-pancreatectomy En Bloc with parcelar gastrectomy for splenic artery aneurysm-a case report and literature review. In Vivo 32: 915-919, 2018.

31. Bacalbasa N, Balescu I, Dima S, Brasoveanu V and Popescu I: Pancreatic resection as part of cytoreductive surgery in advanced-stage and recurrent epithelial ovarian cancer-a single-center experience. Anticancer Res 35: 4125-4129, 2015.

32. Bacalbasa N, Stoica C and Balescu I: Multiple visceral resections for synchronous left and transverse colon adenocarcinoma with gastrocolic-cutaneous fistula-case report and literature review. Anticancer Res 37: 2601-2607, 2017.

33. Bacalbasa $\mathrm{N}$ and Balescu I: Infracolic approach to the superior mesenteric vessels for a large pancreatic tumor with right colon invasion-a case report and literature review. Anticancer Res 37: 2609-2613, 2017.

34. Jones AS and Joergensen EJ: Closure of duodenal wall defects. Surgery 53: 438-442, 1963.

35. Yoshioka I, Matsui K, Okumura T, Yoshida T, Shimada Y and Tsukada K: Pedicled jejunal patch duodenoplasty for traumatic duodenal injury report of a successfully treated case. Am Surg 76: 789-790, 2010.

36. McIlrath DC and Larson RH: Surgical management of large perforations of the duodenum. Surg Clin North Am 51: 857-861, 1971.

37. Hamed S, Guilbaud T, Hardwigsen J and Le Treut IP: Ileal flap duodenoplasty to repair large duodenal defects after R0 resection for malignant tumor to avoid a complex reconstruction:experience with 6 cases. Clin Surg 3: 2110, 2018.

38. Maillet F, Bourgouin S, Gaubert L and Balandraud P: Duodenal reconstruction following extended right colectomy: The pedicled ileal flap technique. J Gastrointest Surg 21: 746-748, 2017. 